\title{
Managing diabetic patients with moderate or severe renal impairment using DPP-4 inhibitors: focus on vildagliptin
}

This article was published in the following Dove Press journal:

Diabetes, Metabolic Syndrome and Obesity:Targets and Therapy

23 April 2013

Number of times this article has been viewed

\author{
Eleonora Russo \\ Giuseppe Penno \\ Stefano Del Prato \\ Department of Clinical and \\ Experimental Medicine, Section of \\ Diabetes and Metabolic Disease, \\ Azienda Ospedaliero Universitaria di \\ Pisa, and University of Pisa, Pisa, Italy
}

Correspondence: Stefano Del Prato Department of Clinical and Experimental Medicine, Section of Diabetes and Metabolic Disease, University of Pisa, Via Paradisa 2, 56124 Pisa, Italy

Tel +3950995103

Fax +3950541521

Email stefano.delprato@med.unipi.it
Background: Dipeptidyl peptidase-4 (DPP-4) inhibitors are novel classified oral anti-diabetic drugs for the treatment of type 2 diabetes mellitus (T2DM) that provide important reduction in glycated hemoglobin, with a low risk for hypoglycemia and no weight gain. In T2DM patients with reduced renal function, adequate glycemic control is essential to delay the progress of kidney dysfunction, but they are at a greater risk of experiencing hypoglycemic events, especially with longer-acting sulfonylureas and meglitinides.

Objective: To evaluate vildagliptin as an option to achieve glycemic control in T2DM patients with moderate or severe chronic kidney disease (CKD).

Methods: A comprehensive search in the literature was performed using the term "vildagliptin." Original articles and reviews exploring our topic were carefully selected.

Results: Vildagliptin provides effective glycemic control in patients with T2DM and CKD. Dose reductions are required for vildagliptin and other DPP-4 inhibitors, except linagliptin, in T2DM patients with moderate-to-severe CKD. Dose of vildagliptin had to be reduced by half (to $50 \mathrm{mg} /$ day) both for moderate (estimated glomerular filtration rate [eGFR] $\geq 30$ to $\leq 50 \mathrm{~mL} / \mathrm{min}$ ) and severe CKD (eGFR $<30 \mathrm{~mL} / \mathrm{min}$ ). Available results support a favorable efficacy, safety, and tolerability profile for vildagliptin in T2DM with moderate or severe renal failure. Preliminary data may suggest additional benefits beyond improvement of glycemic control.

Conclusion: Vildagliptin can be safely used in T2DM patients with varying degrees of renal impairment. Dose adjustments for renal impairment are required. Potential long-term renal benefit of vildagliptin needs to be further explored.

Keywords: type 2 diabetes mellitus, renal function, chronic kidney disease

\section{Introduction}

Type 2 diabetes mellitus (T2DM) is a chronic, progressive disease that requires continuing and demanding medical care in the attempt to reduce the risk of long-term complications. ${ }^{1}$ Genetic and environmental factors concur in sustaining the core pathogenetic mechanisms of diabetes, ie, insulin resistance and pancreatic beta-cell dysfunction. $^{2}$ Although multiple metabolic alterations contribute to the risk of complications in diabetic patients, appropriate management of hyperglycemia remains a main goal of treatment. However, conventional oral anti-diabetic drugs (OADs) have limited impact on glycemic control and can be associated with side effects such as risk of hypoglycemia and/or bodyweight gain. ${ }^{3,4}$ In contrast, therapies such as metformin and those based on the incretin system have the potential to improve glycemic control, minimizing the risk of hypoglycemia and the weight gain. ${ }^{5}$

Use of OADs can also be limited because of comorbidities. For instance, chronic kidney disease (CKD) is very common in T2DM patients because of diabetes 
itself and because of the large proportion of the T2DM population with advanced age. For the purpose of this review, unless otherwise specified, estimated glomerular filtration rate (eGFR) and CKD have been defined based on the National Kidney Foundation Kidney Disease Outcomes Quality Initiative (NKF KDOQI) classification as normal eGFR $\geq 90 \mathrm{~mL} / \mathrm{min} / 1.73 \mathrm{~m}^{2}$ (stage $1 \mathrm{CKD}$ if albuminuria is increased); mildly reduced eGFR $60-89 \mathrm{~mL} / \mathrm{min} / 1.73 \mathrm{~m}^{2}$ (stage $2 \mathrm{CKD}$ if albuminuria is increased); moderately reduced eGFR 30-59 mL/min/1.73 $\mathrm{m}^{2}$ (stage $3 \mathrm{CKD}$ ); severely reduced eGFR $>15-29 \mathrm{~mL} / \mathrm{min} / 1.73 \mathrm{~m}^{2}$ (stage $4 \mathrm{CKD}$ ); and end stage renal failure or stage $5 \mathrm{CKD}$ if eGFR $<15 \mathrm{~mL} / \mathrm{min} / 1.73 \mathrm{~m}^{2}$. eGFR has been calculated by the Modification of Diet in Renal Disease formula, unless otherwise specified. ${ }^{6}$

Up to $40 \%$ of hypertensive T2DM patients have some degree of CKD. ${ }^{7}$ Australian data from 3893 patients with T2DM participating in the National Evaluation of the Frequency of Renal Impairment Co-existing with Noninsulin Dependent Diabetes Mellitus (NEFRON) study show that about $23 \%$ had eGFR $\leq 60 \mathrm{~mL} / \mathrm{min} / 1.73 \mathrm{~m}^{2}$, $35 \%$ had elevated urinary albumin to creatinine ratio, and approximately $10 \%$ had both conditions, for a total of $47 \%$ of the diabetic population with CKD. ${ }^{8}$ Similar data have been found among 15,773 adult Italian T2DM patients participating in the Renal Insufficiency and Cardiovascular Events (RIACE) trial. In this patient cohort, 18.7\% had stages $1-2 \mathrm{CKD}, 10.6 \%$ stage $\geq 3$ nonalbuminuric $\mathrm{CKD}$, and $8.2 \%$ stage $\geq 3$ albuminuric CKD, ie, $18.8 \%$ with an eGFR $\leq 60 \mathrm{~mL} / \mathrm{min} / 1.73 \mathrm{~m}^{2}$ (Figure 1$){ }^{9}$

Renal impairment is a well recognized predisposing factor to hypoglycemia due to accumulation of hypoglycemic agents including insulin. ${ }^{10}$ In T2DM patients with eGFR $\leq 60 \mathrm{~mL} / \mathrm{min} / 1.73 \mathrm{~m}^{2}$, insulin requirement is often reduced. ${ }^{11}$ Therefore, hypoglycemia limits the ability to achieve and maintain glycemic control. Nonetheless, maintenance of good glycemic control is essential in T2DM patients with mild-to-moderate CKD in the attempt, together with effective control of other contributing factors, to slow down loss of kidney function (Table 1). ${ }^{12}$

In summary, with the decline of kidney function, careful selection of OADs and appropriate dose adjustment become critical. Metformin is considered the only cardio-protective agent so far available. Therefore, its maintenance even in the face of CKD has been advocated, though its dose should be reduced for eGFR $<45 \mathrm{~mL} / \mathrm{min} / 1.73 \mathrm{~m}^{2}$ and withdrawn for eGFR $<30 \mathrm{~mL} / \mathrm{min} / 1.73 \mathrm{~m}^{2} .{ }^{13}$ Much caution is needed for sulfonylureas, especially glyburide, and glinides; and a dose reduction is appropriate for an eGFR $<60 \mathrm{~mL} / \mathrm{min} / 1.73 \mathrm{~m}^{2}$. There is no need of dose adjustment for pioglitazone, though its propensity to cause fluid retention should be kept in mind. Alpha-glucosidase inhibitors are not recommended mainly because of lack of safety data. Finally, insulin therapy is difficult to manage because of the mentioned increased risk of hypoglycemia (Table 2).

Because of all the above limitations, interest has grown with respect to the potential use of the incretin-based therapy: the glucagon-like peptide 1 (GLP-1) receptor agonists and the dipeptidyl peptidase-4 (DPP-4) inhibitors. For GLP-1 receptor agonists, information is scanty. Exenatide should be used with caution in subjects with eGFR $30-50 \mathrm{~mL} / \mathrm{min} / 1.73 \mathrm{~m}^{2}$, and it is not recommended for eGFR $<30 \mathrm{~mL} / \mathrm{min} / 1.73 \mathrm{~m}^{2}$ or in patients with

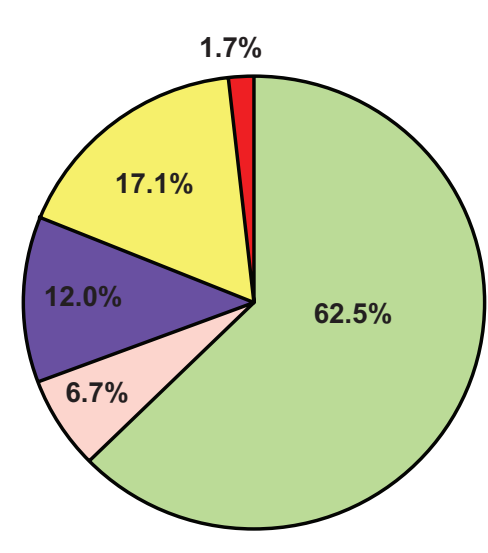

$\square$ No CKD

$\square$ CKD stage 1

$\square$ CKD stage 2

$\square$ CKD stage 3

$\square$ CKD stages $4 / 5$

Approximately $40 \%$ of

patients with T2DM show

signs of CKD (stages 1-5)

Approximately $20 \%$ of

patients with T2DM show

signs of renal failure

$\left(\mathrm{eGFR}<60 \mathrm{~mL} / \mathrm{min} / 1.73 \mathrm{~m}^{2}\right.$ )

Figure I Renal dysfunction is common in patients with type 2 diabetes.

Note: Data are from an Italian cohort of 15,773 patients with T2DM aged 20 years or older participating in the Renal Insufficiency and Cardiovascular Events (RIACE) trial in years 2007-2008. ${ }^{9}$ 
Table I Association between glycemic control and adverse cardiorenal outcomes in people with type 2 diabetes and chronic kidney disease

\begin{tabular}{|c|c|c|c|c|c|}
\hline & \multicolumn{5}{|l|}{ HbA $_{\text {Ic }}$ levels } \\
\hline & \multirow{2}{*}{$\begin{array}{l}<7 \% \\
n=10,709 \text { (stage } 3)\end{array}$} & \multicolumn{2}{|c|}{ Stage 3 CKD } & \multicolumn{2}{|c|}{ Stage 4 CKD } \\
\hline & & $\begin{array}{l}\%-9 \% \\
n=8060\end{array}$ & $\begin{array}{l}>9 \% \\
n=2386\end{array}$ & $\begin{array}{l}7 \%-9 \% \\
n=793\end{array}$ & $\begin{array}{l}>9 \% \\
\mathbf{n}=\mathbf{2 7 6}\end{array}$ \\
\hline All-cause mortality & 1 & $\begin{array}{l}1.04 \\
(0.96-1.13)\end{array}$ & $\begin{array}{l}1.35 \\
(1.20-1.53)\end{array}$ & $\begin{array}{l}1.03 \\
(0.87-1.2 I)\end{array}$ & $\begin{array}{l}1.39 \\
(1.10-1.76)\end{array}$ \\
\hline All-cause hospitalization & 1 & $\begin{array}{l}1.09 \\
(1.04-1.15)\end{array}$ & $\begin{array}{l}1.44 \\
(1.36-1.52)\end{array}$ & $\begin{array}{l}1.13 \\
(1.02-1.25)\end{array}$ & $\begin{array}{l}1.25 \\
(1.01-1.54)\end{array}$ \\
\hline Myocardial infarction & 1 & $\begin{array}{l}1.33 \\
(1.16-1.53)\end{array}$ & $\begin{array}{l}1.85 \\
(1.53-2.25)\end{array}$ & $\begin{array}{l}1.35 \\
(0.85-2.15)\end{array}$ & $\begin{array}{l}2.35 \\
(1.32-4.18)\end{array}$ \\
\hline Stroke & 1 & $\begin{array}{l}1.24 \\
(1.05-1.46)\end{array}$ & $\begin{array}{l}1.96 \\
(1.56-2.47)\end{array}$ & $\begin{array}{l}1.64 \\
(1.00-2.7 I)\end{array}$ & $\begin{array}{l}1.20 \\
(0.5 \mathrm{I}-2.80)\end{array}$ \\
\hline Heart failure & 1 & $\begin{array}{l}1.32 \\
(1.18-1.48)\end{array}$ & $\begin{array}{l}1.89 \\
(1.6 I-2.2 I)\end{array}$ & $\begin{array}{l}1.16 \\
(0.89-1.52)\end{array}$ & $\begin{array}{l}1.32 \\
(0.88-1.98)\end{array}$ \\
\hline ESRD & 1 & $\begin{array}{l}1.22 \\
(0.80-1.86)\end{array}$ & $\begin{array}{l}2.52 \\
(1.58-4.02)\end{array}$ & $\begin{array}{l}1.03 \\
(0.78-1.35)\end{array}$ & $\begin{array}{l}1.13 \\
(0.80-1.59)\end{array}$ \\
\hline $\begin{array}{l}\text { Doubling of serum creatinine } \\
\text { level }\end{array}$ & 1 & $\begin{array}{l}1.10 \\
(0.95-1.26)\end{array}$ & $\begin{array}{l}1.77 \\
(1.48-2.13)\end{array}$ & $\begin{array}{l}I .05 \\
(0.78-I .4 I)\end{array}$ & $\begin{array}{l}1.40 \\
(1.17-1.67)\end{array}$ \\
\hline
\end{tabular}

Notes: A total of 23,296 people with diabetes mellitus and an estimated glomerular filtration rate lower than $60 \mathrm{~mL} / \mathrm{min} / \mathrm{I} .73 \mathrm{~m}{ }^{2}$ were identified within the Alberta Kidney Disease Network, Canada. Over the median follow-up period of 46 months, 3665 people died and 401 developed ESRD. The table highlights adjusted risk of adverse outcomes among people with stage 3 and stage $4 \mathrm{CKD}$, by baseline $\mathrm{HbA}_{1} \cdot{ }^{12}$

Abbreviations: CKD, chronic kidney disease; ESRD, end-stage renal disease; $\mathrm{HbA}_{\mathrm{lc}}$, glycated hemoglobin.

end-stage renal disease (ESRD). Similarly, liraglutide is not recommended in patients with moderate-to-severe renal function impairment, including ESRD patients.

The DPP-4 inhibitors enhance glucose-dependent insulin secretion by preventing DPP-4-mediated degradation of endogenously released incretin hormones. These agents are rapidly becoming a common choice for combination therapy with metformin. ${ }^{5}$ Sitagliptin was approved in 2006, followed by vildagliptin (available in the EU and other countries since 2007, still pending for approval in the US), saxagliptin in 2009, alogliptin in 2010 in Japan, and linagliptin in 2011 in the US and a year later in the EU. Despite their common mechanism of action, these agents have structural heterogeneity that translates into different pharmacological properties. DPP-4 inhibitors differ in terms of half-life, systemic exposure, bioavailability, protein binding, metabolism, presence of active metabolites, and excretion routes. These differences may become of interest when considered for patients with renal failure. While sitagliptin, vildagliptin, and saxagliptin have prominent renal elimination, linagliptin is mainly eliminated through the enterohepatic system. All DPP-4 inhibitors can be used in mild (stages 1 and 2) CKD, with no need for dose adjustment. However, for eGFR $<50 \mathrm{~mL} / \mathrm{min} / 1.73 \mathrm{~m}^{2}$, a dose reduction is required for all DPP-4 inhibitors, with the exception of linagliptin (Table 3). Accumulation in plasma of DPP-4 inhibitors is considered a potential risk not because of hypoglycemia but, possibly, because of unknown adverse events (AEs)..$^{14}$ The dose of sitagliptin must be halved (to $50 \mathrm{mg} /$ day) in patients with moderate

Table 2 Use of conventional antidiabetic drugs in type 2 diabetic patients with chronic kidney disease

\begin{tabular}{|c|c|c|c|c|}
\hline & $\begin{array}{l}\text { eGFR } \\
>60 \mathrm{~mL} / \mathrm{min}\end{array}$ & $\begin{array}{l}\text { eGFR } \\
30-59 \mathrm{~mL} / \mathrm{min}\end{array}$ & $\begin{array}{l}\text { eGFR } \\
<30 \mathrm{~mL} / \mathrm{min}\end{array}$ & Dialysis \\
\hline Insulin & $\checkmark$ & $\checkmark$ & $\begin{array}{l}\checkmark \\
\text { dose reduction }\end{array}$ & $\begin{array}{l}\checkmark \\
\text { dose reduction }\end{array}$ \\
\hline Metformin & $\checkmark$ & $\checkmark$ caution & $\theta$ & $\theta$ \\
\hline Sulfonylureas & $\checkmark$ & caution & caution & $\theta$ \\
\hline Metiglinides & $\checkmark$ & $\checkmark$ caution & caution & $\theta$ \\
\hline Thiazolidinediones & $\checkmark$ & $\checkmark$ caution & $\checkmark$ caution & $\checkmark$ caution \\
\hline $\begin{array}{l}\text { Alpha-glucosidase } \\
\text { inhibitors }\end{array}$ & $\checkmark$ & $\checkmark$ & $\theta$ & $\theta$ \\
\hline
\end{tabular}

Note: $Q$, use not allowed.

Abbreviation: eGFR, estimated glomerular filtration rate. 
Table 3 Dipeptidyl peptidase-4 inhibitors and glucagon-like peptide-I receptor agonists treatments in type 2 diabetic patients with chronic kidney disease

\begin{tabular}{|c|c|c|c|c|c|}
\hline & $\begin{array}{l}\text { Renal } \\
\text { excretion }\end{array}$ & $\begin{array}{l}\text { eGFR } \\
>60 \mathrm{~mL} / \mathrm{min}\end{array}$ & $\begin{array}{l}\text { eGFR } \\
30-59 \mathrm{~mL} / \mathrm{min}\end{array}$ & $\begin{array}{l}\text { eGFR } \\
<30 \mathrm{~mL} / \mathrm{min}\end{array}$ & Dialysis \\
\hline Sitagliptin & Predominant & 100 mg & $50 \mathrm{mg}$ & $25 \mathrm{mg}$ & $25 \mathrm{mg}$ \\
\hline Vildagliptin & Intermediate & $100 \mathrm{mg}$ & $50 \mathrm{mg}$ & $50 \mathrm{mg}$ & $\begin{array}{l}50 \mathrm{mg} \\
\text { caution }\end{array}$ \\
\hline Saxagliptin & Predominant & $5 \mathrm{mg}$ & $2.5 \mathrm{mg}$ & $\begin{array}{l}2.5 \mathrm{mg} \\
\text { caution }\end{array}$ & $\begin{array}{l}2.5 \mathrm{mg} \\
\text { caution }\end{array}$ \\
\hline Linagliptin & Low & $5 \mathrm{mg}$ & $5 \mathrm{mg}$ & $5 \mathrm{mg}$ & $?$ \\
\hline Alogliptin & Predominant & $12.5-25.0 \mathrm{mg}$ & $?$ & $?$ & $?$ \\
\hline Exenatide & Predominant & $5-10 \mu g / d a y$ & Caution & $\theta$ & $\theta$ \\
\hline Liraglutide & No & $0.6-1.8 \mathrm{mg} / \mathrm{day}$ & $\begin{array}{l}0.6-1.8 \mathrm{mg} / \mathrm{day} \\
\text { (caution) }\end{array}$ & $\theta$ & $Q$ \\
\hline
\end{tabular}

Note: ?, unknown; $Q$, use not allowed.

Abbreviation: eGFR, estimated glomerular filtration rate.

(eGFR $\geq 30 \mathrm{~mL} / \mathrm{min} / 1.73 \mathrm{~m}^{2}$ to $\leq 60 \mathrm{~mL} / \mathrm{min} / 1.73 \mathrm{~m}^{2}$ ) and to a quarter (25 mg/day) for those with severe CKD (eGFR $<30 \mathrm{~mL} / \mathrm{min} / 1.73 \mathrm{~m}^{2}$ ). Both saxagliptin and vildagliptin have to be halved for moderate-to-severe and severe CKD. ${ }^{14}$ Kidney function should be checked on a regular basis and metformin discontinued if eGFR falls to $<30 \mathrm{~mL} / \mathrm{min} / 1.73 \mathrm{~m}^{2}$. To this regard, it is of interest to observe that the Study of Treatment and Prevalence of Renal Disease in UK Diabetes Mellitus Type 2 Patients (STARDUST) found that $23 \%$ of patients with eGFR between 30 and $45 \mathrm{~mL} / \mathrm{min} / 1.73 \mathrm{~m}^{2}$ and $32 \%$ of those with eGFR $<30 \mathrm{~mL} / \mathrm{min} / 1.73 \mathrm{~m}^{2}$ were prescribed with metformin. ${ }^{15}$

\section{Chemistry and pharmacokinetics of vildagliptin}

Vildagliptin is a rapidly absorbed, orally active, potent, selective and reversible DPP-4 inhibitor, effective and well tolerated in T2DM patients, either as monotherapy or in combination with other OADs. ${ }^{16}$ DPP-4 inhibition results in increased GLP-1 concentrations, which reduce glucose by suppressing glucagon and stimulating insulin release in a glucose-dependent manner. At 10,25 , and $100 \mathrm{mg}$ twice daily, with or without foods, vildagliptin deeply inhibits DPP-4 (>90\%), with linear pharmacokinetics and a dose-dependent duration of inhibition. Plasma protein binding is low (9.3\%), and absolute bioavailability is high (85\%), with extensive distribution into the extravascular spaces. The elimination half-life of vildagliptin is $2-3$ hours, with steady-state kinetics reached in about 2 days. Eighty-five percent of the administered vildagliptin or its metabolites are excreted with the urine, and the rest is eliminated via the feces. Vildagliptin has no significant P450-related metabolism, so that risk of drug-to-drug interaction is unlikely. In particular, there is no pharmacokinetic interaction between vildagliptin and metformin, pioglitazone or glyburide, allowing safe combination with other OADs.

The main route of elimination of vildagliptin is hydrolysis by multiple tissues or organs, with only approximately $25 \%$ of the drug excreted unchanged by the kidneys. The DPP-4 enzyme contributes to formation of the major metabolite (LAY151), suggesting that vildagliptin is a substrate of DPP-4. In T2DM patients with various degrees of renal failure, vildagliptin exposure increases in a manner that does not strictly correlate with the severity of renal impairment since the kidney contributes to both excretion and hydrolysis of drug. Therefore, the kidneys play only a partial role in vildagliptin elimination. ${ }^{16}$ There is no significant alteration in vildagliptin pharmacokinetics in patients with mild renal impairment (eGFR $\leq 80$ and $>50 \mathrm{~mL} / \mathrm{min} / 1.73 \mathrm{~m}^{2}$ ), so that dose adjustment is not required. ${ }^{17}$ In patients with moderateto-severe renal impairment, both vildagliptin and LAY151 eliminations are affected and their plasma concentrations increased..$^{18}$

\section{Clinical pharmacodynamic of vildagliptin}

A single dose of $10-400 \mathrm{mg}$ of vildagliptin induces a $>90 \%$ inhibition of DPP-4 activity between 0.5 and 4.5 hours post-dose. With doses of 50 and $100 \mathrm{mg}$, the DPP-4 inhibition persists up to 8.5 hours and 12.5 hours post-administration, respectively. The DPP-4 inhibition is reduced to $35 \%$ at 24 hours for the $100 \mathrm{mg}$ dose and up to $70 \%$ for doses $>100 \mathrm{mg}$. Since an inhibition of DPP-4 activity $\geq 80 \%$ is needed to ensure a clinically relevant elevation of GLP-1 and glucose-dependent insulinotropic polypeptide (GIP) serum levels, vildagliptin must be 
administered twice a day, rendering the combination with metformin advantageous, as the two drugs have a similar time schedule of administration. ${ }^{19}$

Vildagliptin increases the concentration of active GLP-1 approximately two- to threefold and those of GIP approximately fivefold. Vildagliptin significantly reduces both fasting and postprandial glucose levels over a dose range of 50-100 mg daily, and there are no substantial additional benefits of doses greater than $50 \mathrm{mg}$ twice daily as monotherapy or in combination with metformin. Vildagliptin has been shown to improve beta-cell function, an improvement that has been confirmed after chronic treatment for up to 2 years. Reduction of the endogenous glucose production contributes to the glucose-lowering effects. Unlike GLP-1 receptor agonists, vildagliptin does not affect gastric emptying, and this accounts for gastrointestinal tolerability. Vildagliptin improves alpha-cell sensitivity to glucose by enhancing suppressive effect of hyperglycemia and stimulatory effect of hypoglycemia. Consistently, a low incidence of hypoglycemic events is recorded when vildagliptin is used both in monotherapy and in combination with other OADs.

Potency of DPP-4 inhibition by vildagliptin has been found to be similar in different ethnic groups. Hepatic impairment, gender, duration of diabetes, insulin resistance, body mass index (BMI), and duration of prior metformin use do not modify pharmacokinetic and efficacy of the drug. ${ }^{20}$ In the elderly ( $>70$ years), vildagliptin exposure is increased by approximately $30 \%$, mainly due to impaired renal function, though this is unlikely to have any clinical relevance. Rather, vildagliptin has been shown to be efficacious, safe, and well tolerated in elderly patients, with no need of dose adjustment. $^{16}$

The glucose-lowering effects of vildagliptin have been investigated in more than 20 randomized, controlled clinical trials, with durations ranging from 12 to 104 weeks, involving $>20,000$ patients. Overall, vildagliptin at the therapeutic dose of $50 \mathrm{mg}$ bid (twice daily) lowered glycated hemoglobin $\left(\mathrm{HbA}_{1 \mathrm{c}}\right)$ levels from baseline by $\sim 1 \%$ in monotherapy and by $\sim 0.8 \%$ when administered as add-on to metformin, thiazolidinediones, sulfonylureas, or insulin. ${ }^{18}$ Improvements in markers of beta-cell function have been consistently reported. In particular, islet function has been shown to improve following administration of vildagliptin in subjects with drug-naïve type 2 diabetes and mild hyperglycemia and in patients with impaired glucose tolerance. ${ }^{21}$ However, whether vildagliptin may prevent progression to diabetes has not been yet determined. Finally, studies have suggested that vildagliptin may improve glucose utilization in peripheral tissues. ${ }^{18}$

Specific studies on the effects of DPP-4 inhibitors on lipid profile and blood pressure remain scanty. In the registration studies, vildagliptin treatment has been associated with mild reduction of total cholesterol and lowdensity lipoprotein cholesterol, fasting and post-prandial triglycerides, and a slight increase in high-density lipoprotein cholesterol. ${ }^{22}$ A trend for reduction in systolic and diastolic blood pressure has been also reported. ${ }^{18}$ In a recent metaanalysis of 30 randomized controlled trials, vildagliptin was not associated with the increase of the risk of any AEs as compared with placebo or thiazolidinediones (TZDs), with a more favorable safety profile than sulfonylureas. Overall, vildagliptin is well tolerated, with no increase risk of nausea, hypertension, cough, naso-enterohepatic pharyngitis, flu, and upper respiratory tract infection as compared with comparators. Similarly, the incidence of fatigue, sinusitis, peripheral edema, tremor, and diarrhea was similar compared with placebo and significantly lower than the one reported with all other active comparators. ${ }^{23}$

\section{DPP-4 inhibitor treatment in patients with impaired renal function}

Data concerning the use of DPP-4 inhibitors in patients with moderate-to-severe renal impairment are mainly derived by post-hoc analysis of the population recruited in the registration trials, but a few ad-hoc studies are available. Arjona Ferreira et al compared the efficacy and safety of sitagliptin versus glipizide in 426 T2DM patients with inadequate glycemic control $\left(\mathrm{HbA}_{1 \mathrm{c}} 7.0 \%-9.0 \%\right)$ and moderate-to-severe chronic renal insufficiency. After 54 weeks of treatment with sitagliptin $(50 \mathrm{mg}$ qd for moderate [eGFR $\geq 30$ to $<50 \mathrm{~mL} / \mathrm{min} / 1.73 \mathrm{~m}^{2}$ ] and $25 \mathrm{mg} \mathrm{qd}$ (once daily) for severe [eGFR $<30 \mathrm{~mL} / \mathrm{min} / 1.73 \mathrm{~m}^{2}$ ] CKD), $\mathrm{HbA}_{1 \mathrm{c}}$ reduction from baseline $(-0.8 \%)$ was noninferior to that obtained with glipizide $(-0.6 \%)$, with a lower incidence of symptomatic hypoglycemia $(6.2 \%$ versus $17.0 \%)$ and a decrease in bodyweight. ${ }^{24}$ Nowicki et al recruited 170 T2DM patients with renal impairment $(\mathrm{CrCl}<50 \mathrm{~mL} / \mathrm{min}$ estimated by the Cockcroft-Gault equation) to be randomized to saxagliptin $2.5 \mathrm{mg}$ once daily or placebo as add-on to any other anti-diabetic drugs in use, including insulin. Patients were stratified as with moderate $(\mathrm{CrCl} \geq 30$ and $<50 \mathrm{~mL} / \mathrm{min})$, severe $(\mathrm{CrCl}<30 \mathrm{~mL} / \mathrm{min}$ and not receiving dialysis), or ESRD on hemodialysis. At week 52, adjusted mean decrease in $\mathrm{HbA}_{1 \mathrm{c}}$ was greater with saxagliptin than with placebo in 
patients with moderate and severe renal impairment, but not in the subgroup with ESRD on hemodialysis. Saxagliptin was generally well tolerated with similar proportions of patients per group reporting hypoglycemic events irrespective of renal impairment severity. ${ }^{25}$

\section{Vildagliptin in mild renal function impairment}

More information is available for vildagliptin. In a retrospective analysis of the GALvus In Addition to metformin versus TZD/metformin in T2DM (GALIANT) study, Banerji et al showed that the safety profile and tolerability of the combination of vildagliptin $100 \mathrm{mg}$ once daily (or TZD) as add-on to metformin in T2DM patients with mild renal impairment $\left(\mathrm{n}=695\right.$, eGFR $>50$ and $\left.\leq 80 \mathrm{~mL} / \mathrm{min} / 1.73 \mathrm{~m}^{2}\right)$ was similar to that observed in patients with normal renal function $\left(\mathrm{n}=1918\right.$, eGFR $\left.>80 \mathrm{~mL} / \mathrm{min} / 1.73 \mathrm{~m}^{2}\right) .{ }^{26} \mathrm{In}$ this 12-week study, the overall incidence of AEs in patients with mild renal impairment (vildagliptin + metformin, $n=464$ : AEs 37.8\%) was comparable to those reported in subjects with normal renal function (vildagliptin + metformin, $\mathrm{n}=1279$ : AEs 40.1\%). Discontinuations due to AEs were comparable for patients with normal renal function and those with mild renal impairment. There was no notable change in transaminase levels from baseline to study-end in both patients with mild renal impairment and normal renal function between vildagliptin and TZD. Serious AEs were more frequent in TZD groups (normal renal function, $2.4 \%$; mild renal failure, $3.0 \%$ ) compared with the vildagliptin groups (normal renal function, 1.6\%; mild renal failure, $2.4 \%$ ). Findings from Schweizer et al showed that vildagliptin monotherapy (compared with metformin) was an effective and well tolerated treatment option in 169 drug-naïve elderly patients with T2DM, $50 \%$ of whom had at least mild renal impairment (eGFR $\geq 50$ to $\left.\leq 80 \mathrm{~mL} / \mathrm{min} / 1.73 \mathrm{~m}^{2}\right) .{ }^{27}$

A recent meta-analysis has pooled data from 38 Phase II and III clinical trials in which vildagliptin was given for $\geq 12-104$ weeks in T2DM patients. The aim was to assess the safety of vildagliptin versus comparators with respect to organs, systems, and tissues of particular interest. ${ }^{28}$ This meta-analysis $(>7000$ subject-years of exposure to vildagliptin $50 \mathrm{mg}$ bid and $>6500$ subject-years exposed to comparators) showed that vildagliptin was not associated with increased risk of hepatic events or hepatic enzyme elevations, pancreatitis, infections, or skin-related toxicity. Although the incidence of AEs across treatments was slightly higher in patients with mild renal impairment (eGFR $\geq 50$ to $\leq 80 \mathrm{~mL} / \mathrm{min} / 1.73 \mathrm{~m}^{2}$ ) compared with patients with normal renal function, the presence of mild renal impairment (more than $30 \%$ of patients exposed to vildagliptin $50 \mathrm{mg}$ qd or bid) did not adversely affect the drug safety. ${ }^{28}$ Incidence of AEs was lower in patients receiving vildagliptin than comparators, irrespective of renal function (mildly impaired versus normal) and age ( $\geq 75$ versus $<75$ years).$^{29}$ However, the number of patients with moderate or severe renal impairment (eGFR $<50 \mathrm{~mL} / \mathrm{min} / 1.73 \mathrm{~m}^{2}$ ) was inadequate to draw final conclusions for these patients.

In summary, at the present time, there is no evidence of a dose-related increase in AEs in T2DM with mild renal impairment treated with vildagliptin.

\section{Vildagliptin in moderate to severe renal function impairment}

A dose of $50 \mathrm{mg}$ once daily was chosen by Lukashevich et al in a much larger, multicenter, randomized, double-blind, placebo-controlled study undertaken to assess safety, tolerability, and efficacy of vildagliptin added to current anti-diabetic therapy in 515 T2DM patients with moderate (eGFR $\geq 30$ to $<50 \mathrm{~mL} / \mathrm{min} / 1.73 \mathrm{~m}^{2}$ ) or severe $\left(\mathrm{eGFR}<30 \mathrm{~mL} / \mathrm{min} / 1.73 \mathrm{~m}^{2}\right)$ renal impairment. Most patients were already on insulin treatment. ${ }^{30}$ The study population consisted of 165 and 129 patients with moderate and 124 and 97 patients with severe renal failure randomized to vildagliptin versus placebo, respectively. After 24 weeks of treatment, the between-treatment difference in adjusted change in $\mathrm{HbA}_{1 \mathrm{c}}$ was $-0.5 \% \pm 0.1 \%(P<0.0001)$ in subjects with moderately impaired (baseline $\mathrm{HbA}_{1 \mathrm{c}} 7.9 \%$ ) and $-0.6 \% \pm 0.1 \%(P<0.0001)$ in patients with severely impaired renal function (baseline $\mathrm{HbA}_{1 \mathrm{c}} 7.7 \%$ ). Thus, relative to placebo, vildagliptin, added to ongoing anti-diabetic drugs, elicited a robust reduction in $\mathrm{HbA}_{1 \mathrm{c}}$ in patients with moderate or severe $\mathrm{CKD}$, with a safety profile comparable to placebo in both subgroups. This study is unprecedented in terms of number of patients with moderate or severe renal failure exposed to a DPP-4 inhibitor. In particular, with regard to events that are of special interest for DPP-4 inhibitors, there was no signal for hepatic-, skin- or pancreatic-related safety. In patients with severe renal failure, there were more AEs with vildagliptin, largely accounted for by a higher rate of flu. This observation, however, is not confirmed in patients with moderate renal failure and in the recent pooled meta-analyses. ${ }^{28,29}$ Hypoglycemia is a matter of concern in patients with renal failure. A slightly higher rate of hypoglycemia was seen in vildagliptin-treated patients with moderate renal impairment, whereas in T2DM with severe renal failure, hypoglycemia rates were similar for 
vildagliptin and placebo. More importantly, given that vildagliptin-treated patients had better glycemic control as indicated by the lower $\mathrm{HbA}_{1 \mathrm{c}}$ levels, the risk of severe hypoglycemia was very low and similar to placebo in both patients with moderate and severe renal failure. The low risk of hypoglycemia is likely due to improved glucose-dependent insulin secretion and maintenance of glucagon secretion in the occurrence of plasma glucose drop, possibly mediated by the glucagonotropic effect of GIP. ${ }^{31}$ Finally, despite the well known increased CV vulnerability of T2DM patients with renal impairment, there was no increased frequency of cardiac events, in keeping with data from patients with normal renal function or mild renal impairment. ${ }^{32}$

The initial observations by Lukashevich et al have been reevaluated after a 52 week extension of the study. ${ }^{33}$ The efficacy of the drug was maintained throughout this period of observation with $\mathrm{HbA}_{1 \mathrm{c}}$ reductions that remained by and large unchanged from week 24 to week 52 . This long-term extension study supports a sufficient degree of durability of treatment effect in T2DM patients with impaired kidney function. Of value, a larger proportion of vildagliptin-treated patients achieved a target $\mathrm{HbA}_{1 \mathrm{c}}<7.0 \%$. The overall rate of hypoglycemia in patients with severe renal impairment also remained low, with no difference between vildagliptin and placebo, with actually a lower risk of severe hypoglycemia in vildagliptin-treated patients in spite of common use of insulin. The incidence of hypoglycemia with vildagliptin in this study (26\% in patients with moderate renal impairment and $18 \%$ in those with severe renal failure) appears to be lower than the one expected ( $\geq 50 \%$ ) in patients with long-standing T2DM and low baseline $\mathrm{HbA}_{1 \mathrm{c}}$ receiving insulin with or without OADs. Again, the putative mechanistic explanation for such a protective effect of vildagliptin most likely relies on increased GIP-mediated stimulation of glucagon release in response to initial plasma glucose reduction. ${ }^{34}$

In summary, this large long-term intervention trial in T2DM patients with moderate or severe renal failure supports the efficacious and safe use of vildagliptin in this vulnerable patient population. ${ }^{30,33}$

\section{Vildagliptin in ESRD}

The effect of vildagliptin in T2DM patients with ESRD on hemodialysis has been directly assessed in a 24-week, prospective, open-label, controlled study. ${ }^{35}$ Vildagliptin, given to 30 patients at $50-100 \mathrm{mg}$ /day, decreased $\mathrm{HbA}_{1 \mathrm{c}}$ levels from $6.7 \%$ to $6.1 \%$. Consensually, postprandial plasma glucose decreased from 186 to $140 \mathrm{mg} / \mathrm{dL}$ in the absence of serious AEs such as severe hypoglycemia or liver impairment. Although long-term follow-up of these patients is necessary to confirm this efficacy, vildagliptin could be considered as an alternative to insulin in patients on hemodialysis. Long-term observation is also advisable with respect to safety. Very recently, two cases of pancreatitis associated with incretin-based therapies in ESRD patients undergoing dialysis have been reported: a 75-year-old woman with a history of liraglutide use and a 68-year-old man on vildagliptin. ${ }^{36}$ Whether, ESRD may represent a condition at high risk for pancreatitis remains to be elucidated. In a meta-analysis of the data from 38 Phase II and III clinical trials, vildagliptin use was not associated with any increase in the incidence of acute pancreatitis over a treatment period ranging from 12 weeks to 2 years. ${ }^{28,29}$ More recently, a randomized, double-blind study enrolling 129 T2DM patients reported that treatment with sitagliptin or glipizide monotherapy was effective and well tolerated over 54 weeks in patients with ESRD on dialysis. ${ }^{37}$

\section{Effects of vildagliptin treatment on the kidney}

Incretin-based agents may exert a beneficial effect in preventing diabetic complications beyond their metabolic effects. Preclinical data have shown that vildagliptin can prevent peripheral nerve degeneration in a diabetes-induced animal model. ${ }^{38}$ Sitagliptin possesses anti-inflammatory and anti-apoptotic effects in retinal cells and exerts beneficial effects on the blood-retinal barrier integrity in the retinas of Zucker diabetic fatty rats. ${ }^{39}$ DPP-4 inhibitors increase availability of GLP-1 in a range of tissues. GLP-1 receptors are expressed in the proximal tubules, in the renal glomerulus, and on podocytes. Hyperglycemia can impair GLP-1 action and downregulate GLP-1 receptor expression in the kidney. Moreover, renal inflammation can upregulate DPP-4 expression in renal glomeruli, while DPP-4 inhibition can upregulate GLP-1 receptor expression. In human proximal tubular cells, GLP-1 receptor agonist may inhibit the advanced glycation end product (AGE)-receptor for AGE (RAGE)-mediated asymmetric dimethylarginine generation via inhibition of reactive oxygen species generation, thereby providing protection against the development and progression of diabetic kidney damage. ${ }^{40}$ In human mesangial cells, exendin-4, a GLP-1 receptor agonist, inhibits cell proliferation and downregulates the expression of transforming growth factor (TGF)- 31 ) and connective tissue growth factor (CTGF) induced by high glucose. ${ }^{41}$ TGF- $\beta 1$ and CTGF induce extracellular matrix accumulation and persistent fibrosis in the glomerular mesangium. Moreover, DPP-4 substrates 
other than incretins, such as brain natriuretic peptide, atrial natriuretic peptide, and stromal-derived factor-1 alpha have proven renal (and cardiovascular) effects. ${ }^{42}$

In summary, a plausible mechanism can be invoked for a role of DPP-4 inhibition in protecting the kidney independently and beyond glycemic control.

\section{Vildagliptin and the kidney in diabetic animal models}

In keeping with the potential mechanisms through which DPP-4 inhibition may exert a protective effect on the diabetic kidney, Liu et al have recently reported that vildagliptin attenuates kidney injury in streptozotocin-induced diabetic rats. ${ }^{43}$ In this animal model, vildagliptin significantly decreased proteinuria, albuminuria, and urinary albumin to creatinine ratio. Moreover, a dose-dependent delay in glomerular basement membrane thickening, tubule-interstitial fibrosis, and glomerulosclerosis was observed. The study also reported improvements in GFR over the 24 weeks of the study. All these effects were apparently independent of blood glucose control.

Chronic treatment with sitagliptin has been shown to attenuate renal ischemia-reperfusion injury (IRI) in diabetic rats. ${ }^{44}$ Sitagliptin-treated diabetic rats that underwent renal IRI showed a significant decrease in serum creatinine levels compared with renal IRI in untreated diabetic rats. Concomitantly, a decreased lipid peroxidation, xanthine oxidase and myeloperoxidase activities, and nitric oxide level in renal tissue were observed along with an increase in antioxidant enzymes like glutathione, glutathione peroxidase, superoxide dismutase, and catalase, and reduced DNA fragmentation and apoptosis.

Consistently, acute DPP-4 inhibition with vildagliptin was found to exert a dose-dependent protective effect on kidney function after IRI in a nondiabetic rat model, as indicated by a decrease of tubular necrosis and inhibition of the apoptotic pathway in the renal proximal epithelial cells. These protective effects were associated with antiapoptotic, immunological, and antioxidative changes. ${ }^{45}$

A potential protective effect of vildagliptin can be derived from the results reported by Wang et al. ${ }^{46}$ These authors studied the effect of NWT-03, an egg protein hydrolysate with DPP-4 and angiotensin-converting-enzyme inhibitory activity, on renovascular damage in Zucker diabetic fatty rats developing signs of kidney damage, such as albuminuria and glomerulosclerosis. Vildagliptin was used as positive control for DPP-4 inhibition. Long-term supplementation with NWT-03 attenuated renovascular damage, and the comparison with vildagliptin led to the conclusion that the effects of NWT-03 were mediated, at least in part, through DPP-4 inhibition since vildagliptin elicited favorable effects on renal proinflammatory cytokines independently of systemic improvement of metabolic parameters.

\section{Vildagliptin and the kidney in humans}

The molecular and preclinical studies lend support to the hypothesis that DPP-4 inhibition may exert a direct nephro-protective effect, providing the basis for exploratory evaluation in the human setting. With respect to this, it is worth recalling the experience of Kothny et al. ${ }^{33}$ These authors have assessed the safety and efficacy of vildagliptin versus placebo, added to ongoing stable antidiabetic treatment over a 52-week randomized follow-up. eGFR was determined to show a slight decline over the 1-year follow-up in both treatment groups.

In patients with moderate renal function impairment, the mean eGFR change from baseline was -1.62 and $-1.80 \mathrm{~mL} / \mathrm{min} / 1.73 \mathrm{~m}^{2}$ in patients on vildagliptin and placebo, respectively. In patients with severe renal failure, the mean change from baseline was -1.98 and $-2.44 \mathrm{~mL} / \mathrm{min} / 1.73 \mathrm{~m}^{2}$ in patients on vildagliptin and placebo, respectively.

In the study by Arjona Ferreira et al, sitagliptin was compared with glipizide. ${ }^{24}$ With both treatments, a similar decline in eGFR was observed (week 54, sitagliptin, $-3.9 \mathrm{~mL} / \mathrm{min} / 1.73 \mathrm{~m}^{2}$; glipizide, $-3.3 \mathrm{~mL} / \mathrm{min} / 1.73 \mathrm{~m}^{2}$ ). Of the randomized patients with moderate renal insufficiency at baseline, 28 out of 149 (18.8\%) on sitagliptin and 17 out of $154(11.0 \%)$ on glipizide progressed to severe renal insufficiency during the study. The changes from baseline in urine albumin/creatinine ratio at week 54 did not differ between treatments.

Interestingly, a pooled analysis of Phase III, placebocontrolled, registration studies showed a significant reduction in urinary albumin excretion after 24 weeks of treatment with linagliptin in subjects with increased albuminuria. ${ }^{47}$

Altogether, the observations suggest a potential direct nephro-protective effect of DPP-4 inhibitors that goes beyond their glucose-lowering effects. With these benefits confirmed, DPP-4 inhibitors may provide an added benefit with respect to renal protection, which may become relevant on the light of the data generated by the National Veterans Health Administration databases study comparing the effectiveness of OADs on kidney function. ${ }^{48}$ This is a retrospective cohort analysis including 93,577 diabetic patients who filled an incident OAD prescription for metformin, sulfonylurea, or rosiglitazone. The primary composite outcome consisted 
of a persistent decline in eGFR from baseline $\geq 25 \%$ or a diagnosis of ESRD, and the secondary outcome included an eGFR event, ESRD, or death. As compared with metformin, use of sulfonylureas was associated with a greater risk of death as well of a decline in eGFR and of ESRD.

\section{Conclusion}

In T2DM patients with moderate or severe renal failure, vildagliptin, a member of the DPP-4 inhibitor family that increases availability of GLP-1 and GIP, maintains an antihyperglycemic efficacy that is not inferior to the one observed in subjects with normal renal function, with a longlasting $\mathrm{HbA}_{1 \mathrm{c}}$ reduction of $0.6 \%-0.8 \% .^{30,33}$

This efficacy is coupled with a favorable safety profile in term of bodyweight neutrality and low risk of hypoglycemia. ${ }^{34}$ Thus, vildagliptin offers new, safe, and promising opportunities for assuring satisfactory glycemic control in T2DM patients with impaired renal function. Whether the favorable risk-to-benefit ratio of vildagliptin in this selected vulnerable population may also provide cardiovascular protection remains, at the present time, a speculation..$^{22}$ Ad hoc studies exploring cardiovascular risk profile and possibly hard cardiovascular endpoint would be more than welcome, as loss of kidney function carries an excess of risk for cardiovascular mortality. ${ }^{32,49}$ For the time being, vildagliptin can be considered a valid option for ensuring glycemic control while avoiding bodyweight gain and reducing the risk of hypoglycemia. Obviously, in treating these patients, appropriate dose reduction of vildagliptin must be considered, given the fact that vildagliptin and its metabolite are largely excreted through the urinary tract.

Of interest, mechanisms have been pointed out in preclinical studies to support a potential nephro-protection effect that is independent of improvement in glucose control. ${ }^{43}$ These intriguing results provide the background for designing studies exploring such a possibility in human T2DM.

\section{Disclosure}

Eleonora Russo and Giuseppe Penno disclose no conflicts of interest. Stefano Del Prato has received consultancy fees from Boehringer Ingelheim, Bristol-Myers Squibb/AstraZeneca, Merck Sharp and Dohme, Novartis Pharmaceuticals, and Takeda Pharmaceuticals.

\section{References}

1. American Diabetes Association. Standard of medical care in diabetes 2013. Diabetes Care. 2013;36(Suppl 1):S11-S66.

2. Tahrani AA, Bailey CJ, Del Prato S, Barnett AH. Management of type 2 diabetes: new and future developments in treatment. Lancet. 2011;378: 182-197.
3. Phung OJ, Scholle JM, Talwar M, Coleman CI. Effect of noninsulin antidiabetic drugs added to metformin therapy on glycemic control, weight gain, and hypoglycemia in type 2 diabetes. JAMA. 2010;303: $1410-1418$.

4. Gross JL, Kramer CK, Leitão CB, et al; for Diabetes and Endocrinology Meta-analysis Group (DEMA). Effect of antihyperglycemic agents added to metformin and a sulfonylurea on glycemic control and weight gain in type 2 diabetes: a network meta-analysis. Ann Intern Med. 2011;154:672-679.

5. Karagiannis T, Paschos P, Paletas K, Matthews DR, Tsapas A Dipeptidyl peptidase-4 inhibitors for treatment of type 2 diabetes mellitus in the clinical setting: systematic review and meta-analysis. BMJ. 2012;344:e1369.

6. National Kidney Foundation. K/DOQI clinical practice guidelines for chronic kidney disease: evaluation, classification, and stratification. $\mathrm{Am}$ J Kidney Dis. 2002;39 (2 Suppl 1):S1-S266.

7. Koro CE, Lee BH, Bowlin SJ. Antidiabetic medication use and prevalence of chronic kidney disease among patients with type 2 diabetes mellitus in the United States. Clin Ther. 2009;31:2608-2617.

8. Thomas MC, Weekes AJ, Broadley OJ, Cooper ME, Mathew TH The burden of chronic kidney disease in Australian patients with type 2 diabetes (the NEFRON study). Med J Aust. 2006;185:140-144.

9. Penno G, Solini A, Bonora E, et al; for Renal Insufficiency And Cardiovascular Events (RIACE) Study Group. Clinical significance of nonalbuminuric renal impairment in type 2 diabetes. $J$ Hypertens. 2011;29:1802-1809.

10. Abe M, Okada K, Soma M. Antidiabetic agents in patients with chronic kidney disease and end-stage renal disease on dialysis: metabolism and clinical practice. Curr Drug Metab. 2011;12:57-69.

11. Moen MF, Zhan M, Hsu VD, et al. Frequency of hypoglycemia and its significance in chronic kidney disease. Clin J Am Soc Nephrol. 2009;4: 1121-1127.

12. Shurraw S, Hemmelgarn B, Lin M, et al; for Alberta Kidney Disease Network. Association between glycemic control and adverse outcomes in people with diabetes mellitus and chronic kidney disease: a population-based cohort study. Arch Intern Med. 2011;171: 1920-1927.

13. Lipska KJ, Bailey CJ, Inzucchi SE. Use of metformin in the setting of mild-to-moderate renal insufficiency. Diabetes Care. 2011;34: 1431-1437.

14. Fonseca VA. Incretin-based therapies in complex patients: practical implications and opportunities for maximizing clinical outcomes: a discussion with Dr Vivian A Fonseca. Am J Med. 2011;124(Suppl 1):S54-S61.

15. Lee S, Bilous R. STARDUST - study of the treatment and prevalence of renal disease in UK diabetes mellitus type 2 patients. Diabetologia. 2011;54(Suppl 1):S128, A293.

16. He YL. Clinical pharmacokinetics and pharmacodynamics of vildagliptin. Clin Pharmacokinet. 2012;51:147-162.

17. Pratley RE, Rosenstock J, Pi-Sunyer FX, et al. Management of type 2 diabetes in treatment-naive elderly patients: benefits and risks of vildagliptin monotherapy. Diabetes Care. 2007;30:3017-3022.

18. Baetta R, Corsini A. Pharmacology of dipeptidyl peptidase-4 inhibitors: similarities and differences. Drugs. 2011;71:1441-1467.

19. Guarino E, Nigi L, Patti A, Fondelli C, Dotta F. Combination therapy with metformin plus vildagliptin in type 2 diabetes mellitus. Expert Opin Pharmacother. 2012;13:1377-1384.

20. Schweizer A, Dejager S, Foley JE. Impact of insulin resistance, body mass index, disease duration, and duration of metformin use on the efficacy of vildagliptin. Diabetes Ther. 2012;3:8.

21. Foley JE, Bunck MC, Möller-Goede DL, et al. Beta cell function following 1 year vildagliptin or placebo treatment and after 12 week washout in drug-naive patients with type 2 diabetes and mild hyperglycaemia: a randomised controlled trial. Diabetologia. 2011;54: 1985-1991.

22. Monami M, Lamanna C, Desideri CM, Mannucci E. DPP-4 inhibitors and lipids: systematic review and meta-analysis. Adv Ther. 2012;29: $14-25$. 
23. Cai L, Cai Y, Lu ZJ, Zhang Y, Liu P. The efficacy and safety of vildagliptin in patients with type 2 diabetes: a meta-analysis of randomized clinical trials. J Clin Pharm Ther. 2012;37:386-398.

24. Arjona Ferreira JC, Marre M, Barzilai N, et al. Efficacy and safety of sitagliptin versus glipizide in patients with type 2 diabetes and moderate-to-severe chronic renal insufficiency. Diabetes Care. Epub December 17, 2012.

25. Nowicki M, Rychlik I, Haller H, et al. Long-term treatment with the dipeptidyl peptidase-4 inhibitor saxagliptin in patients with type 2 diabetes mellitus and renal impairment: a randomised controlled 52-week efficacy and safety study. Int J Clin Pract. 2011;65:1230-1239.

26. Banerji MA, Purkayastha D, Francis BH. Safety and tolerability of vildagliptin vs thiazolidinedione as add-on to metformin in type 2 diabetic patients with and without mild renal impairment: a retrospective analysis of the GALIANT study. Diabetes Res Clin Pract. 2010;90: 182-190.

27. Schweizer A, Dejager S, Bosi E. Comparison of vildagliptin and metformin monotherapy in elderly patients with type 2 diabetes: a 24-week, double-blind, randomized trial. Diabetes Obes Metab. 2009;11:804-812.

28. Ligueros-Saylan M, Foley JE, Schweizer A, Couturier A, Kothny W. An assessment of adverse effects of vildagliptin versus comparators on the liver, the pancreas, the immune system, the skin and in patients with impaired renal function from a large pooled database of Phase II and III clinical trials. Diabetes Obes Metab. 2010;12:495-509.

29. Schweizer A, Dejager S, Foley JE, Shao Q, Kothny W. Clinical experience with vildagliptin in the management of type 2 diabetes in a patient population $\geq 75$ years: a pooled analysis from a database of clinical trials. Diabetes Obes Metab. 2011;13:55-64.

30. Lukashevich V, Schweizer A, Shao Q, Groop PH, Kothny W. Safety and efficacy of vildagliptin versus placebo in patients with type 2 diabetes and moderate or severe renal impairment: a prospective 24-week randomized placebo-controlled trial. Diabetes Obes Metab. 2011;13:947-954.

31. Farngren J, Persson M, Schweizer A, Foley JE, Ahrén B. Vildagliptin reduces glucagon during hyperglycemia and sustains glucagon counterregulation during hypoglycemia in type 1 diabetes. J Clin Endocrinol Metab. 2012;97:3799-3806.

32. Schweizer A, Dejager S, Foley JE, Couturier A, Ligueros-Saylan M, Kothny W. Assessing the cardio-cerebrovascular safety of vildagliptin: meta-analysis of adjudicated events from a large Phase III type 2 diabetes population. Diabetes Obes Metab. 2010;12:485-494.

33. Kothny W, Shao Q, Groop PH, Lukashevich V. One-year safety, tolerability and efficacy of vildagliptin in patients with type 2 diabetes and moderate or severe renal impairment. Diabetes Obes Metab. 2012;14:1032-1039.

34. Christensen M, Vedtofte L, Holst JJ, Vilsbøll T, Knop FK. Glucose-dependent insulinotropic polypeptide: a bifunctional glucose-dependent regulator of glucagon and insulin secretion in humans. Diabetes. 2011;60:3103-3109.

35. Ito M, Abe M, Okada K, et al. The dipeptidyl peptidase-4 (DPP-4) inhibitor vildagliptin improves glycemic control in type 2 diabetic patients undergoing hemodialysis. Endocr J. 2011;58:979-987.
36. Nakata H, Sugitani S, Yamaji S, et al. Pancreatitis with pancreatic tail swelling associated with incretin-based therapies detected radiologically in two cases of diabetic patients with end-stage renal disease. Intern Med. 2012;51:3045-3049.

37. Arjona Ferreira JC, Corry D, Mogensen CE, et al. Efficacy and safety of sitagliptin in patients with type 2 diabetes and ESRD receiving dialysis: a 54-week randomized trial. Am J Kidney Dis. Epub January 23, 2013.

38. Jin HY, Liu WJ, Park JH, Baek HS, Park TS. Effect of dipeptidyl peptidase-IV (DPP-IV) inhibitor (Vildagliptin) on peripheral nerves in streptozotocin-induced diabetic rats. Arch Med Res. 2009;40: 536-544.

39. Gonçalves A, Leal E, Paiva A, et al. Protective effects of the dipeptidyl peptidase IV inhibitor sitagliptin in the blood-retinal barrier in a type 2 diabetes animal model. Diabetes Obes Metab. 2012;14:454-463.

40. Ojima A, Ishibashi Y, Matsui T, et al. Glucagon-like Peptide-1 receptor agonist inhibits asymmetric dimethylarginine generation in the kidney of streptozotocin-induced diabetic rats by blocking advanced glycation end product-induced protein arginine methyltranferase-1 expression. Am J Pathol. 2013;182:132-141.

41. Li W, Cui M, Wei Y, Kong X, Tang L, Xu D. Inhibition of the expression of TGF- 31 and CTGF in human mesangial cells by exendin-4, a glucagon-like peptide-1 receptor agonist. Cell Physiol Biochem. 2012;30:749-757.

42. Hocher B, Reichetzeder C, Alter ML. Renal and cardiac effects of DPP-4 inhibitors - from preclinical development to clinical research. Kidney Blood Press Res. 2012;36:65-84.

43. Liu WJ, Xie SH, Liu YN, et al. Dipeptidyl peptidase IV inhibitor attenuates kidney injury in streptozotocin-induced diabetic rats. $J$ Pharmacol Exp Ther. 2012;340:248-255.

44. Vaghasiya J, Sheth N, Bhalodia Y, Manek R. Sitagliptin protects renal ischemia reperfusion induced renal damage in diabetes. Regul Pept. 2011;166:48-54.

45. Glorie LL, Verhulst A, Matheeussen V, et al. DPP-4 inhibition improves functional outcome after renal ischemia-reperfusion injury. Am J Physiol Renal Physiol. 2012;303:F681-F688.

46. Wang Y, Landheer S, van Gilst WH, et al. Attenuation of renovascular damage in Zucker diabetic fatty rat by NWT-03, an egg protein hydrolysate with ACE- and DPP4-inhibitory Activity. PLoS One. 2012; 7:e46781

47. Groop P-H, Cooper M, Perkovic V, et al. Effects of the DPP-4 inhibitor linagliptin on albuminuria in patients with type 2 diabetes and diabetic nephropathy. Diabetologia. 2012;55(Suppl 1):S20, A36.

48. Hung AM, Roumie CL, Greevy RA, et al. Comparative effectiveness of incident oral antidiabetic drugs on kidney function. Kidney Int. 2012;81:698-706.

49. Panchapakesan U, Mather A, Pollock C. Role of GLP-1 and DPP-4 in diabetic nephropathy and cardiovascular disease. Clin Sci (Lond). 2013;124:17-26.

\section{Publish your work in this journal}

Diabetes, Metabolic Syndrome and Obesity: Targets and Therapy is an international, peer-reviewed open-access journal committed to the rapid publication of the latest laboratory and clinical findings in the fields of diabetes, metabolic syndrome and obesity research. Original research, review, case reports, hypothesis formation, expert opinion and commentaries are all considered for publication. The manuscript management system is completely online and includes a very quick and fair peer-review system, which is all easy to use. Visit http://www.dovepress.com/testimonials.php to read real quotes from published authors. 